\title{
Prediction of Responses in a Sustainable Dry Turning Operation: A Comparative Analysis
}

\author{
Shibaprasad Bhattacharya $\left(\mathbb{D},{ }^{1}\right.$ Partha Protim Das $\mathbb{D}^{2},{ }^{2}$ Prasenjit Chatterjee $\mathbb{D}^{\mathrm{D}},{ }^{3}$ \\ and Shankar Chakraborty $\mathbb{D}^{1}$ \\ ${ }^{1}$ Department of Production Engineering, Jadavpur University, Kolkata, West Bengal, India \\ ${ }^{2}$ Department of Mechanical Engineering, Sikkim Manipal Institute of Technology, Sikkim Manipal University, Majitar, \\ Sikkim, India \\ ${ }^{3}$ Department of Mechanical Engineering, MCKV Institute of Engineering, Howrah, West Bengal, India \\ Correspondence should be addressed to Prasenjit Chatterjee; p.chatterjee@mckvie.edu.in
}

Received 16 March 2021; Accepted 20 May 2021; Published 30 May 2021

Academic Editor: Zeljko Stevic

Copyright (C) 2021 Shibaprasad Bhattacharya et al. This is an open access article distributed under the Creative Commons Attribution License, which permits unrestricted use, distribution, and reproduction in any medium, provided the original work is properly cited.

\begin{abstract}
In a turning operation, involving removal of material from the outer diameter of a rotating cylindrical workpiece using a singlepoint cutting tool, there exist complex relationships between various cutting parameters and responses. In this paper, a turning operation under dry environment is considered with cutting speed, feed rate, and depth of cut as the input parameters, as well as material removal rate, average surface roughness, and cutting force as the responses. Dry turning operation reduces energy consumption and machining cost, thus eventually resulting in sustainable machining. For the considered process, the corresponding response values are envisaged using four prediction models, that is, multivariate regression analysis, fuzzy logic, artificial neural network, and adaptive neurofuzzy inference system (ANFIS), and their prediction performance is contrasted using five statistical metrics, that is, root mean squared percent error, mean absolute percentage error, root mean squared log error, correlation coefficient, and root relative squared error. It is noticed that ANFIS model consisting of the advantages features of both fuzzy logic and neural network outperforms the other prediction models with respect to the computed values of the considered statistical measures. Based on their acceptable values, it can be propounded that the ANFIS model can be effectively employed for prediction of process responses while treating different machining parameters as the input variables.
\end{abstract}

\section{Introduction}

Manufacturing operations are among the paramount energy-intensive processes that consume large amount of energy and natural resources. Sustainable manufacturing focuses on economically viable machining processes to reduce environmental threats by conserving energy and other resources. Sustainable manufacturing can be defined as manufacturing of products/components using those machining processes which would minimize the negative environmental impacts and conserve energy and natural resources, which would be indirectly safe for the employees, communities, and consumers as well as being economically feasible. In the manufacturing domain, metal machining has now been more focused on adapting the concept of sustainability leading to its improved economic, environmental, and social performance. In conventional machining processes, the generated heat in the cutting zone is one of the major problems as it affects the mechanical properties of the workpiece, wearing out of cutting tool, and deteriorating surface roughness. In this context, improvement in machining conditions has become an imperative issue to dissipate the generated heat by the use of cutting fluids, which are major sources of waste generation and environmental deterioration. These cutting fluids are naturally not biodegradable and require treatment before their disposal. Moreover, when these fluids come in contact with the hot machining zone, they get vaporized producing toxic fumes 
hazardous to the human health. Maintenance of the lubrication system, power consumption, and disposal of cutting fluids are some of the major factors leading to growing environmental issues and increased manufacturing cost. Use of cryogenics can be considered as an alternative to sustainable manufacturing resulting in environmentally toxicfree machining operation with better surface finish. But its high maintenance and installation cost and excessive energy consumption hinder its widespread application. Thus, in the present-day manufacturing scenario, dry machining with no use of cutting fluids has become an optimal solution to sustainable manufacturing. Dixit et al. [1] established that dry machining could be an effective environment-friendly process due to no air and water pollution. Schultheiss et al. [2] also concluded that dry machining could be performed without the use of cutting fluid, while making it a more sustainable material removal method, allowing collection of chips more easily for waste recycling.

In the present-day manufacturing environment, machining is an inevitable operation to provide the desired shape geometry to a given workpiece component. Among all the available machining operations, turning operation using a nonrotary single-point cutting tool plays a key role in removing material from the outer diameter of a rotating cylindrical workpiece, while reducing its diameter to a specified dimension and achieving a smooth finish of the machined component [3]. During turning operation, the workpiece is rotated at a particular cutting speed and the cutting tool is fed against the workpiece at a specific depth of cut. Turning operation is usually performed in a conventional lathe, but when higher dimensional accuracy is required, automated lathe with computer numerical control technology can be employed [4]. It is quite suitable for machining of diverse materials, like hardened steels and alloy steels, heat-treated materials, superalloys, and so forth.

It has been observed that effective turning operation involves selection of various input parameters, like cutting speed $(v)$, feed rate $(f)$, depth of cut $(d)$, nose radius of the tool, types of the work material and cutting tool, machining environment, type of the cutting fluid used, type of the insert, and so forth. On the other hand, the corresponding outputs (responses) are material removal rate (MRR), surface roughness (SR) (with respect to average surface roughness $(\mathrm{Ra})$ ), cutting force $(\mathrm{Fc})$, cutting temperature, tool wear, acceleration, power consumption, and so forth. In order to achieve the desired turning performance with respect to enhanced product quality and reduced energy consumption, machining cost, and tool wear, a suitable combination of all the considered input parameters is always demanded [5]. Due to involvement of a large number of correlated input parameters, as well as high complexity and nonlinearity of the cutting mechanism, development of a representative model exhibiting the interrelationships between the turning parameters and responses seems to be a complicated and difficult task. Development of such mathematical models would usually help in understanding the process behaviour and predicting the responses based on a set of given cutting parameters. With continuous development of computational facilities, applications of various soft computing tools, mainly in the form of fuzzy logic, artificial neural network (ANN), evolutionary algorithms, adaptive neurofuzzy interference system (ANFIS), and so forth, have become quite popular among the research community to explore the unknown relationships between the input and output parameters and predict the machining behaviour with a high degree of accuracy [6].

In predictive modelling, various statistical algorithms and machine learning techniques are usually employed to identify the likelihood of future outcomes based on historical data. It is simply a mathematical process that seeks to foresee future events or outcomes while analyzing existent patterns in the historical data. Its goal is to go beyond knowing what has happened to provide a best assessment of what would happen in future. In this paper, based on a set of 27 pieces of experimental data, an attempt is put forward to envisage values of $\mathrm{Ra}, \mathrm{Fc}$, and MRR using three input parameters $(v, f$, and $d$ ) in a dry turning operation while applying four prediction models, that is, regression analysis, fuzzy logic, ANN, and ANFIS. The relative performance of these prediction models is also compared with respect to some important statistical measures. The effects of turning parameters on the responses under consideration are also investigated.

\section{Literature Review}

Table 1 provides a list of different input turning parameters, responses, and soft computing techniques (prediction models) applied by the past researchers while modelling and predicting the mechanism of cutting operation in dry machining environment. The results of this literature survey in Table 1 show that different mathematical models, mainly in the form of regression analysis, ANN, support vector regression, and ANFIS, have been employed for prediction of different responses based on the given sets of diverse turning parameters. Application of fuzzy logic for modelling and prediction in turning operation is really scarce. It is also observed that those prediction models have been adopted individually for different turning operations and comparative studies with respect to their prediction performance are limited. Keeping in mind this research gap, this paper proposes the simultaneous applications of multivariate regression analysis, fuzzy logic, ANN, and ANFIS for envisaging the responses of a dry turning operation based on the training and testing datasets, and their performances are compared with respect to five statistical metrics, that is, root mean squared percent error (RMSPE), mean absolute percentage error (MAPE), root mean squared log error (RMSLE), correlation coefficient $(R)$, and root relative squared error (RRSE). The corresponding "If-Then" rules for fuzzy logic and ANFIS models are also developed to help the machinist in understanding the influences of various turning parameters on the responses. It is revealed that ANFIS model having the advantages features of both fuzzy logic and ANN outperforms the other prediction models with respect to the considered statistical measures. Effect of different input membership functions on the prediction performance of ANFIS model is also investigated. Thus, application of 
TABLE 1: Turning parameters, responses, and prediction models considered by the past researchers.

\begin{tabular}{|c|c|c|c|c|}
\hline $\begin{array}{l}\text { Sl. } \\
\text { no. }\end{array}$ & Author(s) & Input parameters & Response(s) & Prediction model \\
\hline 1. & Koura et al. [7] & $v, f, d$ & $\mathrm{Ra}$ & ANN \\
\hline 2. & Hanief and Wani [8] & $v, f, d$ & $\mathrm{Ra}$ & Regression \\
\hline 3. & Mia et al. [9] & $\begin{array}{c}v, f \text {, tool configuration, } \\
\text { environment }\end{array}$ & $\mathrm{Ra}$ & ANOVA \\
\hline 4. & Benlahmidi et al. [10] & $v, f, d$, workpiece hardness & $\begin{array}{l}\mathrm{Ra} \text {, cutting pressure, cutting } \\
\text { power }\end{array}$ & Regression \\
\hline 5. & $\begin{array}{c}\text { Sharma and Krishnaiah } \\
{[11]}\end{array}$ & $v, f, d$ & Ra, MRR, power consumption & ANN, regression \\
\hline 6. & Panda et al. [12] & $v, f, d$ & Flank wear, $\mathrm{Ra}$, acceleration & Regression \\
\hline 7. & Pawan and Misra [13] & $v, f$, approach angle & $\mathrm{Ra}$ & Regression \\
\hline 8. & Aouici et al. [14] & $v, f$, cutting time & $\mathrm{Ra}$, specific cutting force, flank wear & Regression \\
\hline 9. & Elbah et al. [15] & $v, f, d$, cutting radius & $\mathrm{Ra}$, cutting force components, tool wear & Regression \\
\hline 10. & $\begin{array}{l}\text { Rajbongshi and Sarma } \\
{[16]}\end{array}$ & $v, f, d$ & $\mathrm{Ra}$, flank wear, $\mathrm{Fc}$, feed force & ANN, regression \\
\hline 11. & $\begin{array}{l}\text { Alajmi and Almeshal } \\
{[17]}\end{array}$ & $v, f, d$ & $\mathrm{Ra}$ & ANFIS \\
\hline 12. & Cica et al. [18] & $v, f, d$, environment & $\begin{array}{l}\text { Machining force, cutting power, cutting } \\
\text { pressure }\end{array}$ & $\begin{array}{l}\text { Regression, support vector } \\
\text { regression, } \\
\text { Gaussian process regression, } \\
\text { ANN }\end{array}$ \\
\hline 13. & Panda et al. [19] & $v, f, d$ & Acceleration, flank wear, $\mathrm{Ra}$ & Regression \\
\hline 14. & Setia and Chauhan [20] & $v, f, d$ & $\begin{array}{l}\text { Cutting force components, cutting } \\
\text { temperature }\end{array}$ & Regression \\
\hline 15. & This paper & $v, f, d$ & $\mathrm{Ra}, \mathrm{Fc}, \mathrm{MRR}$ & $\begin{array}{c}\text { Regression, ANN, fuzzy logic, } \\
\text { ANFIS }\end{array}$ \\
\hline
\end{tabular}

ANFIS model can effectively frame the input-output relationship of the considered turning operation under dry environment.

\section{Prediction Models}

3.1. Regression Analysis. During any experiment, the observed dataset can be utilized to develop the existent relationship between the dependent parameter (response) and independent parameters (inputs) in the following form:

$$
y=f\left(x_{1}, x_{2}, \&, x_{n}\right)+\varepsilon,
$$

where $f$ is the approximate function, $x_{i}(i=1,2, \ldots, n)$ is the $i^{\text {th }}$ input parameter, $y$ is the response, and $\varepsilon$ is the normally distributed statistical error. A quadratic function can also be formulated using the experimental dataset in the following form:

$$
y=\beta_{0}+\sum_{i=1}^{n} \beta_{i} x_{i}+\sum_{i=1}^{n} \sum_{j=i+1}^{n} \beta_{i j} x_{i} x_{j}+\sum_{i=1}^{n} \beta_{i i} x_{i}^{2}+\varepsilon,
$$

where $\beta_{0}$ is the $Y$-intercept coefficient, $\beta_{1}-\beta_{n}$ are the main effect coefficients, and $\beta_{i j}$ is the interaction coefficient. A well-developed regression model has the ability to determine the relative influence of one or more independent variables on the dependent variable and potentiality to identify outliers or anomalies in the dataset. It has also other advantages, like simplicity, interpretability, scientific acceptance, and so forth. But it also suffers from some disadvantages, like inability to deal with qualitative data, lengthy and complicated calculations, unchanged cause and effect relationship between the dependent and independent variables, chances of error during extrapolation, and so forth.

3.2. Fuzzy Logic. Fuzzy set theory, developed by Zadeh [21], deals with incomplete and vague information to achieve a rational conclusion for any problem, while converting the imprecise linguistic terms (such as "high" and "low") into numerical values using fuzzy membership functions. It states that, in a universe of discourse $X$, a fuzzy subset $\tilde{A}$ of $X$ can be expressed using a membership function $f_{\widetilde{A}}(x)$, mapping each element $x$ in $X$ to a real number $R$ in unit interval of $[0,1]$. The function value $f_{\widetilde{A}}(x)$ highlights the grade of membership of $x$ in $\tilde{A}$.

A fuzzy logic unit contains a fuzzifier, membership functions, a fuzzy rule base, an inference engine, and a defuzzifier. In fuzzy-logic-based analysis, the membership functions are the inputs to the fuzzifier to fuzzify the input variables having some degree of uncertainty and ambiguity. A membership function maps each input value to a membership value between 0 and 1 . The inference engine performs a fuzzy reasoning of the developed fuzzy rules to generate the corresponding fuzzy value $[22,23]$. The defuzzifier finally transforms the fuzzy value into a crisp value. A fuzzy rule base consisting of a set of "If-Then" control rules is developed to depict the inference relationship between the input and output. A set of such fuzzy rules is shown as follows [24]: 


$$
\begin{aligned}
& \text { Rule 1: If } x_{1} \text { is } A_{1} \text { and } \mathrm{x}_{2} \text { is } \mathrm{B}_{1} \text { and } x_{3} \text { is } C_{1} \text { and } x_{4} \text { is } D_{1} \text {, Then output }(\mathrm{O}) \text { is } E_{1} \text {, else, } \\
& \text { Rule 2: If } x_{1} \text { is } A_{2} \text { and } \mathrm{x}_{2} \text { is } \mathrm{B}_{2} \text { and } x_{3} \text { is } C_{2} \text { and } x_{4} \text { is } D_{2} \text {, Then output }(\mathrm{O}) \text { is } E_{2} \text {, else, } \\
& \text { Rule } n \text { : If } x_{1} \text { is } A_{n} \text { and } \mathrm{x}_{2} \text { is } \mathrm{B}_{\mathrm{n}} \text { and } x_{3} \text { is } C_{n} \text { and } x_{4} \text { is } D_{n} \text {, Then output(O)is } E_{n} \text {, }
\end{aligned}
$$

where $A_{i}, B_{i}, C_{i}$, and $D_{i}$ are the fuzzy subsets defined by the corresponding membership functions, that is, $\mu_{A i}, \mu_{B i}, \mu_{C i}$, and $\mu_{D i}$, respectively. The inference engine performs fuzzy reasoning on fuzzy rules while considering max-min inference for generating a fuzzy value, $\mu_{c_{0}}(O)$.

$$
\begin{aligned}
\mu_{C_{0}}(O)= & \left(\mu_{A_{1}}\left(x_{1}\right) \wedge \mu_{B_{1}}\left(x_{2}\right) \wedge \mu_{C_{1}}\left(x_{3}\right) \wedge \mu_{D_{1}}\left(x_{4}\right) \wedge \mu_{E_{1}}(O)\right) \vee \\
& \left(\mu_{A_{2}}\left(x_{1}\right) \wedge \mu_{B_{2}}\left(x_{2}\right) \wedge \mu_{C_{2}}\left(x_{3}\right) \wedge \mu_{D_{2}}\left(x_{4}\right) \wedge \mu_{E_{2}}(O)\right) \vee \\
& \left(\mu_{A_{n}}\left(x_{1}\right) \wedge \mu_{B_{n}}\left(x_{2}\right) \wedge \mu_{C_{n}}\left(x_{3}\right) \wedge \mu_{D_{n}}\left(x_{4}\right) \wedge \mu_{E_{n}}(O)\right),
\end{aligned}
$$

where $\wedge$ is the minimum operation and $\vee$ is the maximum operation. Finally, a centric fuzzification method is adopted to convert the fuzzy multiresponse output, $\mu_{c_{0}}(O)$, into a crisp value $(C)$.

$$
C=\frac{\sum O \mu_{C_{0}}(O)}{\sum \mu_{C_{0}}(O)} .
$$

As a prediction tool, fuzzy logic has some advantageous features, like the ability to deal with problems having imprecise and incomplete data, ability to model nonlinear functions of arbitrary complexity, being simple and easily interpretable, no requirement of a large dataset or even any dataset to train the model, and so forth. But fuzzy logic may not be always accurate as the results are perceived based on assumption and human knowledge. Accuracy of fuzzy logic also largely depends on proper selection of the corresponding membership function for mapping the interrelationship between the input and output variables. In fuzzy-logic-based modelling approach, the problem of finding out the appropriate membership functions and fuzzy rules is often an exhausting process of trial and error. It requires the end users to understand the data before training, which is usually difficult for a relatively large dataset.

3.3. ANN. The ANN, biologically inspired from human brain, devours outstanding ability to determine patterns and identify trends from complicated or imperfect dataset which are too complex to perceive by either humans or other computer techniques [25]. It is a computational modelling technique having hundreds of individual processing units (PE) (also called artificial neurons), coupled with coefficients (weights), which form the neural structure. Each PE has weighted inputs, an appropriate transfer function, and an output. Each neuron is capable of processing simple information. However, the real strength of neural computation comes into picture when these neurons are connected to form a network. Compared to $\sim 100$ billion neurons of human brain, ANN has hundred or thousand PEs. The ANN can be classified based on the transfer functions of the neurons, learning rule, and connection formula.

The neurons are the building blocks of an ANN, located in the network layers and designed to simulate functions of the biological neurons. There are input layer, output layer, and hidden layers in a typical ANN architecture. The input signals, multiplied by the corresponding weight factors and added together, are passed through a transfer function to generate the output for a neuron. The activation function is the weighed sum of the inputs to the neurons. The most commonly used transfer functions are pure linear transfer function (purelin) and tangent sigmoid function (tansig). For neuron connection, ANN has different architectures. Among them, feedforward architecture does not have a connection back from the output to the input neurons and, therefore, does not keep a record of its previous output values. On the other hand, feedback architecture has connections from output to input neurons. There are also different training/learning models among which backpropagation model or delta model is most widely utilized.

An ANN is initially trained to map the input dataset while adjusting the weights through a number of iterations. Estimation of the values of these weights is extremely crucial for development of a robust ANN model. The available input information is first fed through the network to derive the optimal weights for the neurons. These optimal weights are obtained using backpropagation of errors during the training/learning phase. The ANN analyzes the input and output values for a dataset and accordingly modifies the weights to bring the predicted values closer to the target values. The error in prediction is minimized through a repeated number of training cycles till it reaches a specified accuracy. A well-structured and trained ANN has an ability to deal with insufficient knowledge, potentiality to learn by itself while providing the output not limited to the input dataset, robust learning method for its effective training, as well as an ability to provide almost accurate results from an erroneous training dataset. On the other hand, ANN, being a black box type approach, suffers from overfitting of data and it does not provide any idea about how a particular response is predicted based on a given set of input variables.

3.4. ANFIS. An ANFIS is a hybrid predictive model integrating the adaptive capability of ANNs and qualitative rulebased reasoning of fuzzy logic [26, 27]. It harnesses the advantageous features of both ANNs and fuzzy logic while utilizing the mathematical properties of ANNs in tuning the rule-based fuzzy systems to approximate the human reasoning approach. In this model, an ANN is employed with the learning and computing capabilities in fuzzy logic, whereas fuzzy logic provides the advanced expert knowledge 
and fuzzy principles for use by the ANN. The integration of ANNs and fuzzy logic in ANFIS architecture makes it more systematic and less dependent on human expertise. It basically provides the mapping relation between the input and output data while employing a hybrid learning method to determine the optimal distribution of membership functions. The ANFIS architecture contains five layers, that is, fuzzy layer, product layer, normalization layer, defuzzification layer, and total output layer, with each layer consisting of several nodes described by the corresponding node function. The inputs to a specific layer are derived from the nodes of the previous layer. In this architecture, a fixed node is represented by a circle, whereas an adaptive node (where the parameters are modified during adaptation or training) is denoted by a square. In order to demonstrate the working principle of ANFIS model, it is assumed that there are two inputs $\left(x\right.$ and $y$ ) and one output $\left(f_{i}\right)$. As it employs the firstorder Sugeno fuzzy inference system, the corresponding rules can be framed as follows [28-30]:

Rule 1: if $x$ is $A_{1}$ and $y$ is $B_{1}$, then $z$ is $f_{1}(x, y)=$ $p_{1} x+q_{1} y+r_{1}$

Rule 2: if $x$ is $A_{2}$ and $y$ is $B_{2}$, then $z$ is $f_{2}(x, y)=$ $p_{2} x+q_{2} y+r_{2}$

Here, $p_{1}, q_{1}, r_{1}, p_{2}, q_{2}$, and $r_{2}$ are the linear parameters (consequent parameters), $A_{1}, B_{1}, A_{2}$, and $B_{2}$ are the nonlinear parameters, and $f_{i}(x, y)$ is the output of the first-order Sugeno fuzzy inference system. The architecture of ANFIS model is exhibited in Figure 1.

In the fuzzy layer, $x$ and $y$ are the input nodes, and $A_{1}, B_{1}$, $A_{2}$, and $B_{2}$ are the linguistic labels in the fuzzy theory (like "low" or "high") for deriving the membership function. This layer consists of adaptive nodes with the following node functions:

$$
\begin{aligned}
& O_{1, i}=\mu_{A_{i}}(x) \text { for } \quad i=1,2, \\
& O_{1, i}=\mu_{B_{i-2}}(y) \text { for } \quad i=3,4,
\end{aligned}
$$

where $\mu(x)$ and $\mu(y)$ are the parameterized membership functions which usually follow bell shape with the maximum and minimum values as 1 and 0 , respectively. With the changing parameter values, the bell-shaped function varies accordingly, thereby allowing various forms of the membership function for fuzzy set.

$$
\mu(x)=\frac{1}{1+\left[\left(x-c_{i}\right)^{2} / a_{i}^{2}\right]^{b_{1}}},
$$

where $a_{i}, b_{i}$, and $c_{i}$ constitute the parameter set. These are also known as premise parameters.

In the product node, every node is a fixed node, with the node function to be multiplied by the input signals to serve as output.

$$
O_{2, i}=w_{i}=\mu_{A i}(x) \times \mu_{B i}(y) \text { for } \quad i=1,2,
$$

where $w_{i}$ represents the firing strength of a rule.

Every node in the third layer is a fixed node, having the node function to normalize the firing strength while computing the ratio of the $i^{\text {th }}$ node's firing strength to the sum of all rules' firing strength.

$$
\mathrm{O}_{3, i}=\overline{w_{i}}=\frac{w_{i}}{\sum w_{i}} \text { for } i=1,2 .
$$

In the fourth layer, every node is an adaptive node. The defuzzification relationship between the input and output of this layer can be expressed as follows:

$$
O_{4, i}=\bar{w}_{i} f_{i}=\bar{w}_{i}\left(p_{i} x+q_{i} y+r_{i}\right) \text { for } \quad i=1,2 .
$$

The last layer of ANFIS model consists of a fixed node, with node function to compute the overall output as

$$
\begin{aligned}
O_{5, i}= & \sum_{i} \bar{w}_{i} f_{i}=\frac{w_{1}}{w_{1}+w_{2}} f_{1}+\frac{w_{1}}{w_{1}+w_{2}} f_{2}, \\
= & \left(w_{1} x\right) p_{1}+\left(w_{1} y\right) q_{1}+\left(w_{1}\right) r_{1}+\left(w_{2} x\right) p_{2} \\
& +\left(w_{2} y\right) q_{2}+\left(w_{2}\right) r_{2} .
\end{aligned}
$$

The ANFIS adopts a hybrid learning algorithm combining the gradient method with the least-squares method to update the parameter values. The consequent parameters are identified by the least-squares estimate in the forward pass of the learning algorithm. On the other hand, the premise parameters are updated by the gradient descent algorithm in the backward pass. Being a hybrid prediction model, ANFIS has the advantages of both ANN and fuzzy logic, like robustness during learning and training, as well as high interpretability. It can deal with numerical as well as linguistic data, and it has the capability of fast learning, better adaptability, and potentiality to cater fuzziness, ambiguity, and uncertainty in the system under consideration. It can also effectively capture the nonlinear structure of a given process. It can be trained without relying solely on expert knowledge as applicable for a fuzzy logic model. Compared to ANN, it is more transparent to the end user with less memorization error. Despite its wide acceptance among the researchers, ANFIS model suffers from limitations, such as curse of dimensionality and computational expense.

\section{Dry Turning Operation}

During dry turning operation using a heavy-duty lathe (HMT Ltd., Model: NH26) on a round bar of AISI 304 stainless steel material (diameter of $60 \mathrm{~mm}$ and length of $200 \mathrm{~mm}$ ), Nayak et al. [31] performed 27 experiments based on $L_{27}$ orthogonal array design plan. For the turning operation, an ISO P30 grade uncoated cemented carbide insert was employed as the cutting tool, and $v, f$, and $d$ were considered as the turning parameters. On the other hand, MRR (in $\mathrm{mm}^{3} / \mathrm{min}$ ), $\mathrm{Fc}$ (in N), and $\mathrm{Ra}$ (in $\mu \mathrm{m}$ ) were treated as the responses/outputs. During the experiments, the setting of each of the turning parameters was varied at three different levels, as shown in Table 2. The experimental design plan along with the measured response values is provided in Table 3. Nayak et al. [31] applied grey relational analysis technique to determine the best parametric intermix of the considered turning parameters to simultaneously optimize 


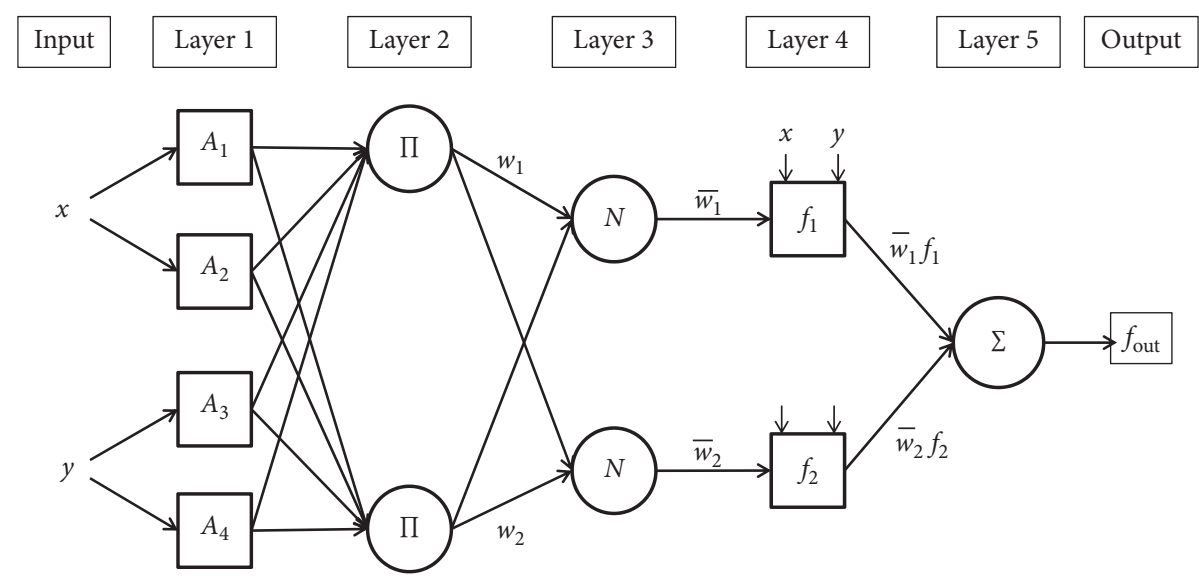

FIgURE 1: ANFIS structure.

TABLE 2: Turning parameters and their operating levels [31].

\begin{tabular}{lcccc}
\hline \multirow{2}{*}{ Turning parameter } & \multirow{2}{*}{ Unit } & \multicolumn{3}{c}{ Level of variation } \\
& & 1 & 2 & 3 \\
\hline Cutting speed & $\mathrm{m} / \mathrm{min}$ & 25 & 35 & 45 \\
Feed rate & $\mathrm{mm} / \mathrm{rev}$ & 0.1 & 0.15 & 0.2 \\
Depth of cut & $\mathrm{mm}$ & 1 & 1.25 & 1.5 \\
\hline
\end{tabular}

TABle 3: Experimental dataset [31].

\begin{tabular}{lccccccc}
\hline Run & $v$ & $f$ & $d$ & $\mathrm{Ra}$ & $\mathrm{Fc}$ & MRR & Purpose \\
\hline 1 & 35 & 0.2 & 1.5 & 0.68 & 1453 & 10500 & Training \\
2 & 25 & 0.2 & 1 & 0.72 & 1090 & 5000 & Training \\
3 & 25 & 0.15 & 1 & 0.61 & 894 & 3750 & Training \\
4 & 35 & 0.1 & 1 & 0.56 & 635 & 3500 & Testing \\
5 & 25 & 0.1 & 1 & 0.49 & 676 & 2500 & Testing \\
6 & 35 & 0.15 & 1 & 0.57 & 839 & 5250 & Training \\
7 & 35 & 0.2 & 1.25 & 0.67 & 1141 & 8750 & Training \\
8 & 45 & 0.15 & 1 & 0.54 & 780 & 6750 & Training \\
9 & 45 & 0.1 & 1 & 0.64 & 605 & 4500 & Testing \\
10 & 25 & 0.15 & 1.25 & 0.62 & 1085 & 4687.5 & Testing \\
11 & 25 & 0.2 & 1.5 & 0.73 & 1549 & 7500 & Training \\
12 & 35 & 0.1 & 1.25 & 0.46 & 770 & 4375 & Training \\
13 & 25 & 0.1 & 1.25 & 0.50 & 820 & 3125 & Training \\
14 & 25 & 0.2 & 1.25 & 0.72 & 1322 & 6250 & Training \\
15 & 45 & 0.2 & 1.25 & 0.64 & 1183 & 11250 & Training \\
16 & 45 & 0.1 & 1.25 & 0.44 & 734 & 5625 & Training \\
17 & 45 & 0.2 & 1 & 0.63 & 975 & 9000 & Testing \\
18 & 25 & 0.15 & 1.5 & 0.62 & 1271 & 5625 & Testing \\
19 & 25 & 0.1 & 1.5 & 0.50 & 962 & 3750 & Training \\
20 & 35 & 0.2 & 1 & 0.67 & 1022 & 7000 & Training \\
21 & 45 & 0.2 & 1.5 & 0.64 & 1386 & 13500 & Training \\
22 & 45 & 0.1 & 1.5 & 0.44 & 860 & 6750 & Training \\
23 & 35 & 0.15 & 1.5 & 0.58 & 1192 & 7875 & Testing \\
24 & 45 & 0.15 & 1.5 & 0.55 & 1137 & 10125 & Testing \\
25 & 35 & 0.15 & 1.25 & 0.57 & 1018 & 6562.5 & Testing \\
26 & 45 & 0.15 & 1.25 & 0.55 & 970 & 8437.5 & Training \\
27 & 35 & 0.1 & 1.5 & 0.46 & 902 & 5250 & Training \\
\hline & & & & & & &
\end{tabular}

all the three responses. A confirmatory experiment was also conducted to validate the derived results. In this paper, 18 and 9 experimental datasets are randomly selected from Table 3 for training and testing purposes of fuzzy logic, ANN, and ANFIS models, respectively.

\section{Prediction of Responses in Dry Turning Operation}

In an attempt to contrast the performance of the considered prediction models, the corresponding response surface methodology-based regression equations are first developed exhibiting the relationships between the turning parameters and responses. From the analysis of variance (ANOVA) results (not shown here due to paucity of space), it can clearly be revealed that $f$ (having $p$ value $<0.05$ ) is the most statistically significant turning parameter (contribution of 90.13\%) influencing $\mathrm{Ra}$ value of the turned components. Similarly, for Fc, $f$ and $d$ are the two most significant turning parameters having $59.77 \%$ and $35.67 \%$ contributions, respectively. In this turning operation, MRR is maximally influenced by $f(55.55 \%$ contribution), followed by $v(20.83 \%$ contribution $)$ and $d$ (20\% contribution). For MRR, some of the two-factor interactions also appear to be statistically significant.

$$
\begin{aligned}
y(R a)= & 0.600-0.00826 \times v+1.542 \times f-0.199 \times d \\
& +0.000081 \times v^{2}+0.85 \times f^{2} \\
& +0.0537 \times d^{2}-0.0020 \times v \times f+0.00051 \times v \\
& \times d+0.559 \times f \times d-0.0074 \times v \times f \times d, \\
y(F c)= & 2757-52.0 \times v-9551 \times f-2096 \times d \\
& +0.313 \times v^{2}+11284 \times f^{2}+555 \times d^{2} \\
& +163 \times v \times f+22.2 \times v \times d+9048 \times f \\
& \times d-147 \times v \times f \times d, \\
y(M R R)= & 4919+35 \times v-23889 \times f-5232 \times d \\
& +0.184 \times v^{2} \\
& +49296 \times f^{2}+1816 \times d^{2}-174 \times v \times f-34 \\
& \times v \times d+7350 \times f \times d+1092 \times v \times f \times d .
\end{aligned}
$$

During dry turning operation, the influences of $v, f$, and $d$ on $\mathrm{Ra}, \mathrm{Fc}$, and MRR are pictorially demonstrated in Figures 2-4. It can be observed that, with increasing values of 
$v$, surface quality of the turned components improves. At lower $v$ value, formation of build-up edge increases due to higher adherence tendency between the tool and workpiece, resulting in poor surface quality. With increasing values of $v$, the cutting temperature also increases, which is responsible for better surface quality. On the other hand, higher values of $f$ result in higher thrust force and vibration, increasing surface roughness of the machined components. It can also be noticed from Figure 2 that a value of $d$ as $1.25 \mathrm{~mm}$ provides better surface finish and its higher value results in poor surface finish due to excessive tool wear. The effects of $v, f$, and $d$ on $\mathrm{Fc}$ are exhibited in Figure 3. It can be revealed that an increase in the value of $v$ causes higher heat generation in the machining zone during dry turning operation, which is responsible for thermal softening of the workpiece material and reduction in cutting forces. Increasing values of both $f$ and $d$ result in higher cutting forces. At higher $f$ values, extra forces are required for the necessary plastic deformation for effective material removal during dry turning operation. In the similar direction, at higher values of $d$, there are increments in the cutting forces due to increase in the effective shear area at the tool and workpiece interface. It can also be noticed from Figure 4 that higher values of $v, f$, and $d$ are all responsible for achieving higher MRR with more amount of material being removed from the workpiece.

In this paper, fuzzy logic designer, neural network toolbox, and neurofuzzy designer of MATLAB (2016a) are, respectively, employed for prediction of the responses using fuzzy logic, ANN, and ANFIS models. The prediction model based on fuzzy logic consists of three inputs, three outputs, and Mamdani inference system, and it generates 18 rules using the training dataset to envisage values of the considered machining responses for different combinations of turning parameters. For this fuzzy logic model, the type of the input and output membership functions is considered as generalized bell-shaped. Figure 5 exhibits the fuzzy rule viewer and the first rule from this figure is presented as follows.

If $v=25 \mathrm{~m} / \mathrm{min}, f=0.1 \mathrm{~mm} / \mathrm{rev}$, and $d=1 \mathrm{~mm}$, then $\mathrm{Ra}=0.556 \mu \mathrm{m}, \mathrm{Fc}=767 \mathrm{~N}$, and $\mathrm{MRR}=3045 \mathrm{~mm}^{3} / \mathrm{min}$.

In the similar direction, the developed architecture for the ANN model with three nodes in the input layer, ten nodes in the hidden layer, and three nodes in the output layer is exhibited in Figure 6. As there are three turning parameters and three responses in the prediction model, the corresponding ANN architecture also consists of three input and three output layers. To have the minimum mean squared error (MSE) value along with a well-trained network, the number of nodes in the hidden layer is chosen as ten based on trial-and-error method. Addition of a greater number of nodes in the hidden layer would unnecessarily increase the ANN architecture with further increase in the training time. For training of this ANN model, Levenberg-Marquardt backpropagation algorithm is employed, whereas hyperbolic tangent sigmoid transfer function and pure linear transfer function are, respectively, utilized in the hidden layer and output layer.
In fuzzy logic and ANFIS models, choice of the most appropriate membership function for the input variables depends on the number of rules in the fuzzy inference system, mechanism of the fuzzy inference system, and defuzzification process. Like in the fuzzy logic model, in ANFIS model, generalized bell is also chosen as the membership function for the input variables due to its higher reliability, robustness, and ability to represent the inputoutput relationships more efficiently. Besides the generalized bell function, triangular, trapezoidal, and Gaussian can also be adopted as the membership functions for the input variables in ANFIS model. Figure 7 represents a typical generalized bell membership function, and the ANFIS architecture along with the related training parameters is provided in Table 4. The ANFIS architecture obtained from MATLAB Toolbox is exhibited in Figure 8.

In this ANFIS model, as there are three input parameters and a membership function with three levels ("low", "medium," and "high"), altogether $3^{3}=27$ rules are framed for each of the responses. The rule viewer developed for $\mathrm{Ra}$ is portrayed in Figure 9. As mentioned earlier, from the initial dataset with 27 experimental observations, 9 experimental runs are randomly utilized for testing of the ANFIS model. The predicted values of $\mathrm{Ra}, \mathrm{Fc}$, and MRR are provided in Table 5 . It can be clearly noted from the first row of the rule viewer in Figure 9 that when $v=25 \mathrm{~m} / \mathrm{min}, f=0.1 \mathrm{~mm} / \mathrm{rev}$, and $d=1 \mathrm{~mm}$, the value of Ra is obtained as $0.528 \mu \mathrm{m}$. From the other two rule viewers for Fc and MRR (not shown in this paper due to paucity of space), it can also be observed that, for this combination of $v, f$, and $d$, the predicted values of Fc and MRR are $682 \mathrm{~N}$ and $2579 \mathrm{~mm}^{3} / \mathrm{min}$, respectively. The comparisons between the actual Ra, Fc, and MRR values and their predicted values for all the four prediction tools are, respectively, presented in Figures 10-12. It can be revealed from these figures that the values of $\mathrm{Ra}, \mathrm{Fc}$, and MRR predicted using the developed ANFIS model closely match with their respective actual values. On the other hand, the prediction performance of regression analysis and ANN model is not at all satisfactory.

The prediction performance of the considered models is now validated based on various statistical metrics. The RMPSE is a popular measure to define the goodness of fit of a developed model that best describes the average percent error in predicting the considered turning responses. The mean absolute percentage error of the predicted values with respect to the actual values is estimated using MAPE. In RMSLE, introduction of the logarithm makes it possible to consider the relative difference between the actual and predicted values, while estimating percentual difference between them. It treats small differences between small actual and predicted values approximately the same as big differences between large actual and predicted values. The degree of association between the actual and predicted responses is estimated using $R$ value. On the other hand, RRSE takes the total squared error and normalizes it while dividing by the total squared error of the simple predictor. While taking the square root of the relative squared error, the error is reduced to the same dimension as the response being predicted. Among these statistical metrics, lower values are 


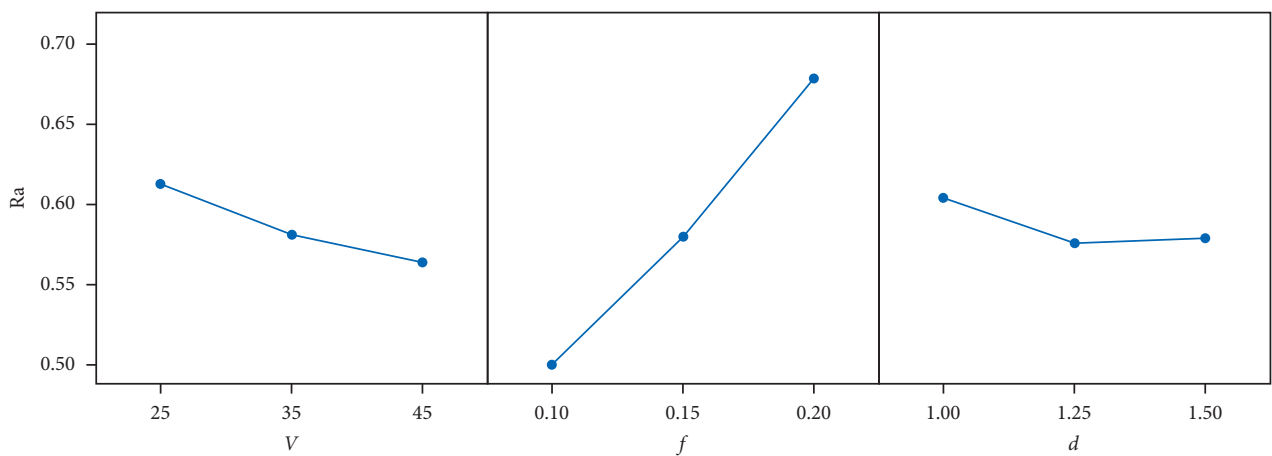

FIGURE 2: Effects of dry turning parameters on Ra.

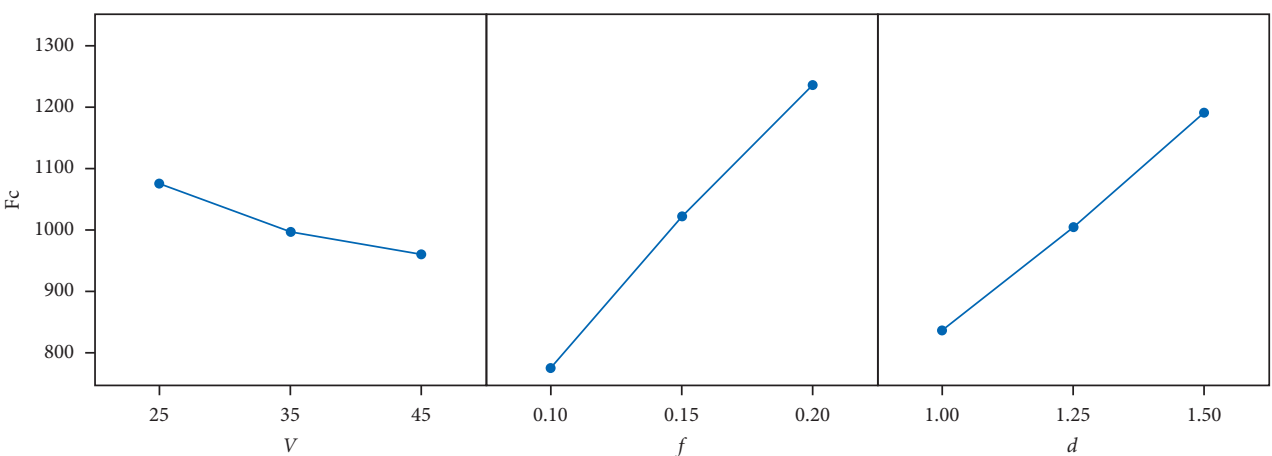

FIGURE 3: Effects of dry turning parameters on Fc.

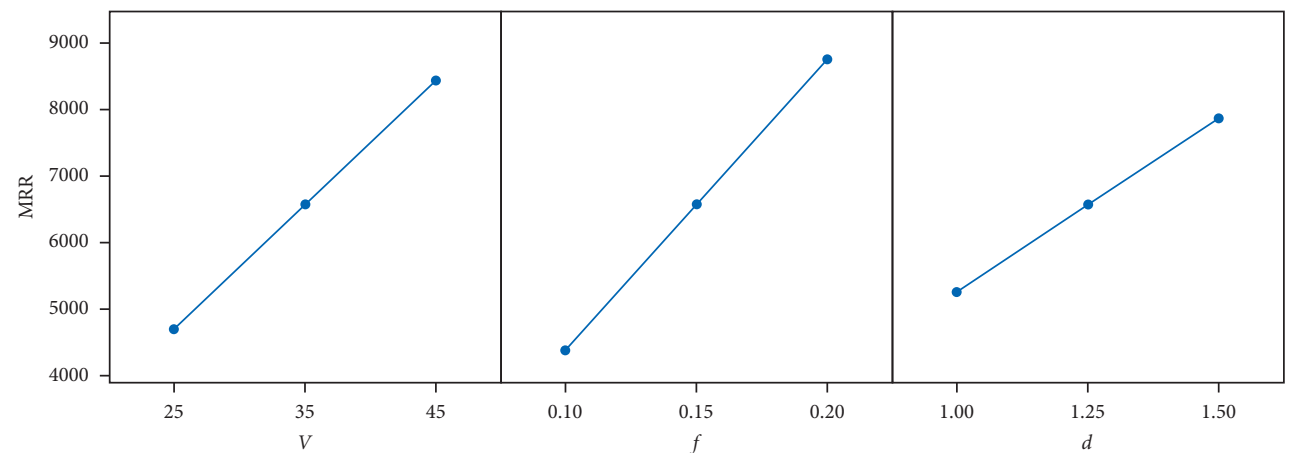

FIGURE 4: Effects of dry turning parameters on MRR.

required for RMSPE, MAPE, RMSLE, and RRSE, while higher $R$ value is always preferred to validate the performance of any prediction tool. The mathematical formulations of these statistical metrics are presented as follows:

$$
\begin{aligned}
\mathrm{RMSPE} & =\sqrt{\frac{1}{n} \sum_{i=1}^{n}\left(\frac{A_{i}-P_{i}}{A_{i}}\right)^{2}} \times 100, \\
\mathrm{MAPE} & =\frac{1}{n} \sum_{i=1}^{n}\left|\frac{A_{i}-P_{i}}{A_{i}}\right| \times 100,
\end{aligned}
$$

$$
\text { RMSLE }=\sqrt{\frac{1}{n} \sum_{i=1}^{n}\left(\log \left(P_{i}+1\right)-\log \left(A_{i}+1\right)\right)^{2}},
$$

$$
R=\frac{\sum_{i=1}^{n}\left(A_{i}-\bar{A}\right)(P-\bar{P})}{\sqrt{\sum_{i=1}^{n}(A-\bar{A})^{2}(P-\bar{P})^{2}}}
$$

$$
\mathrm{RRSE}=\sqrt{\frac{\sum_{i=1}^{n}\left(P_{i}-A_{i}\right)^{2}}{\sum_{i=1}^{n}\left(A_{i}-\bar{A}\right)^{2}}}
$$



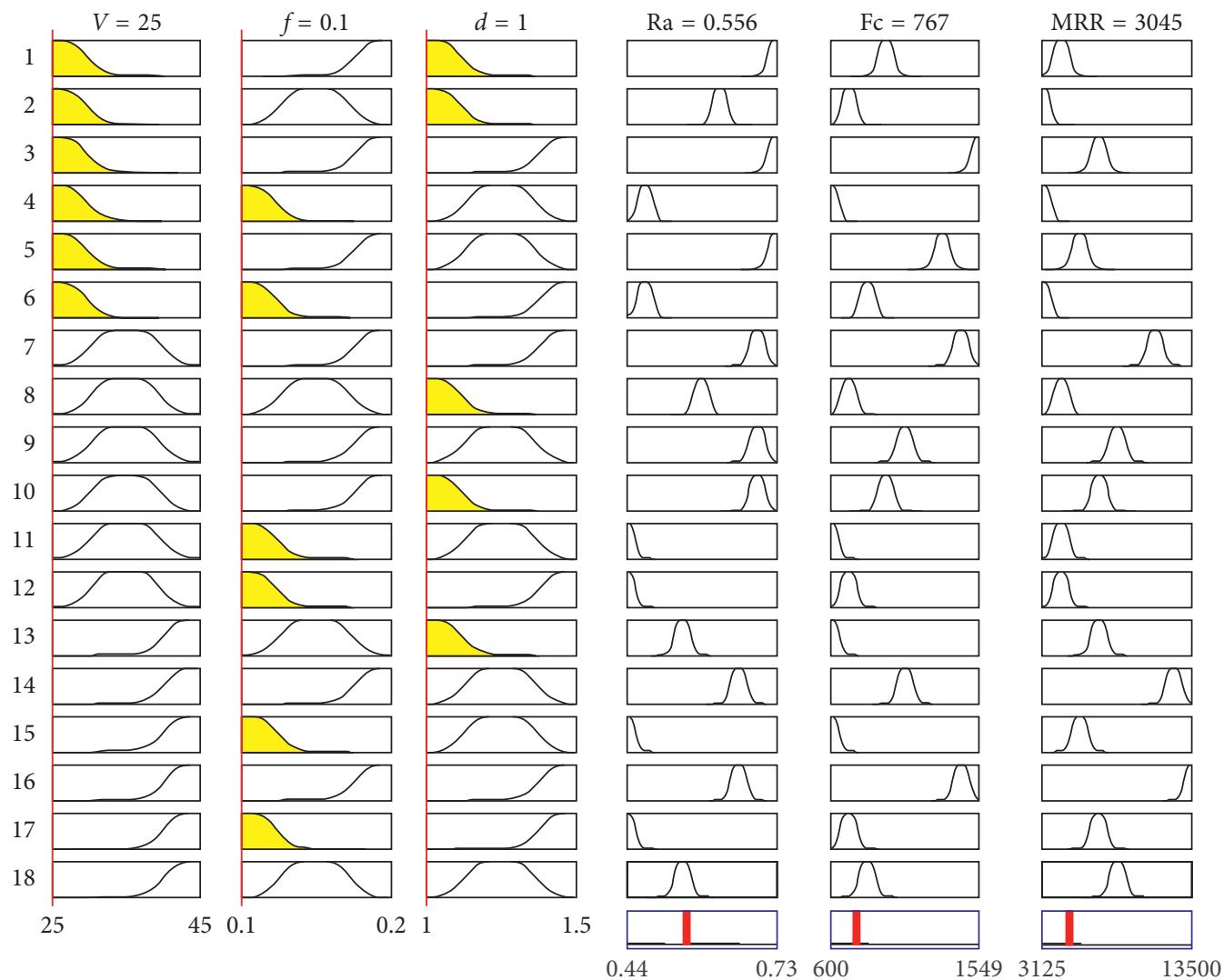

Figure 5: Fuzzy rule viewer.

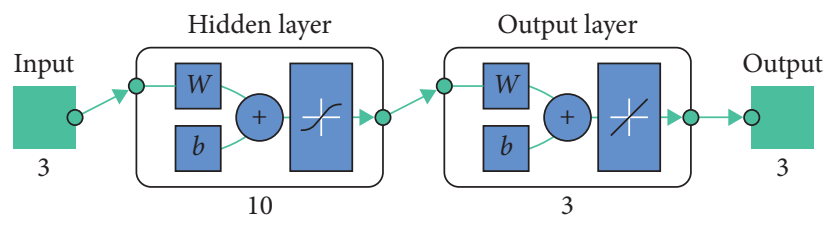

FIgURE 6: Developed ANN architecture.

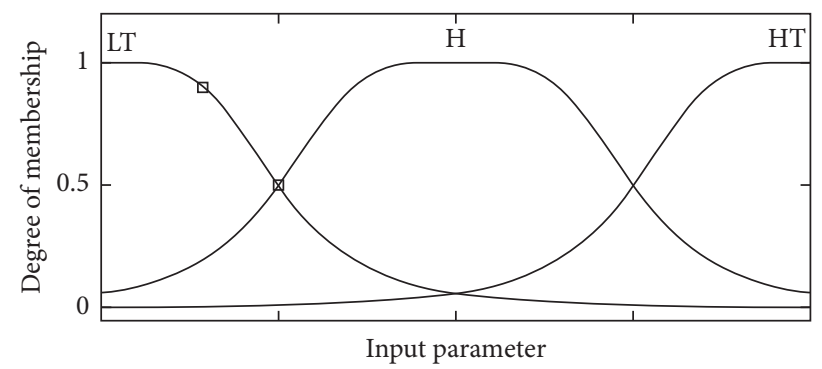

Figure 7: A generalized bell membership function.

where $A_{i}$ and $P_{i}$ are the actual and predicted response values, $\bar{A}$ and $\bar{P}$ are the means of all the actual and predicted response values, and $n$ is the total number of observations in the testing dataset. Table 6 provides values of RMSPE, MAPE, RMSLE, $R$, and RRSE for the testing dataset when regression analysis, fuzzy logic, ANN, and ANFIS models are employed for prediction of $\mathrm{Ra}, \mathrm{Fc}$, and MRR values during the dry turning operation. These comparison results for $\mathrm{Ra}$, Fc, and MRR values are also pictorially exhibited in Figures 13-15, respectively. From these figures, it can be noticed that ANFIS model excels over the others with respect to all the statistical measures for the three turning responses under consideration. Finally, the prediction performance of ANFIS model itself is contrasted in Table 7 for four different 
TABLE 4: ANFIS architecture and training parameters.

\begin{tabular}{lc}
\hline Number of layers & 5 \\
\hline Size of the input dataset & $18 \times 3$ \\
Number of outputs & 3 \\
Membership function & Generalized bell \\
Learning rules & Least-square estimation gradient descent algorithm \\
Inference system & Sugeno inference system \\
Training method & Hybrid method \\
Number of rules generated & 27 \\
Momentum constant & 0.9 \\
Number of epochs & 500 \\
\hline
\end{tabular}

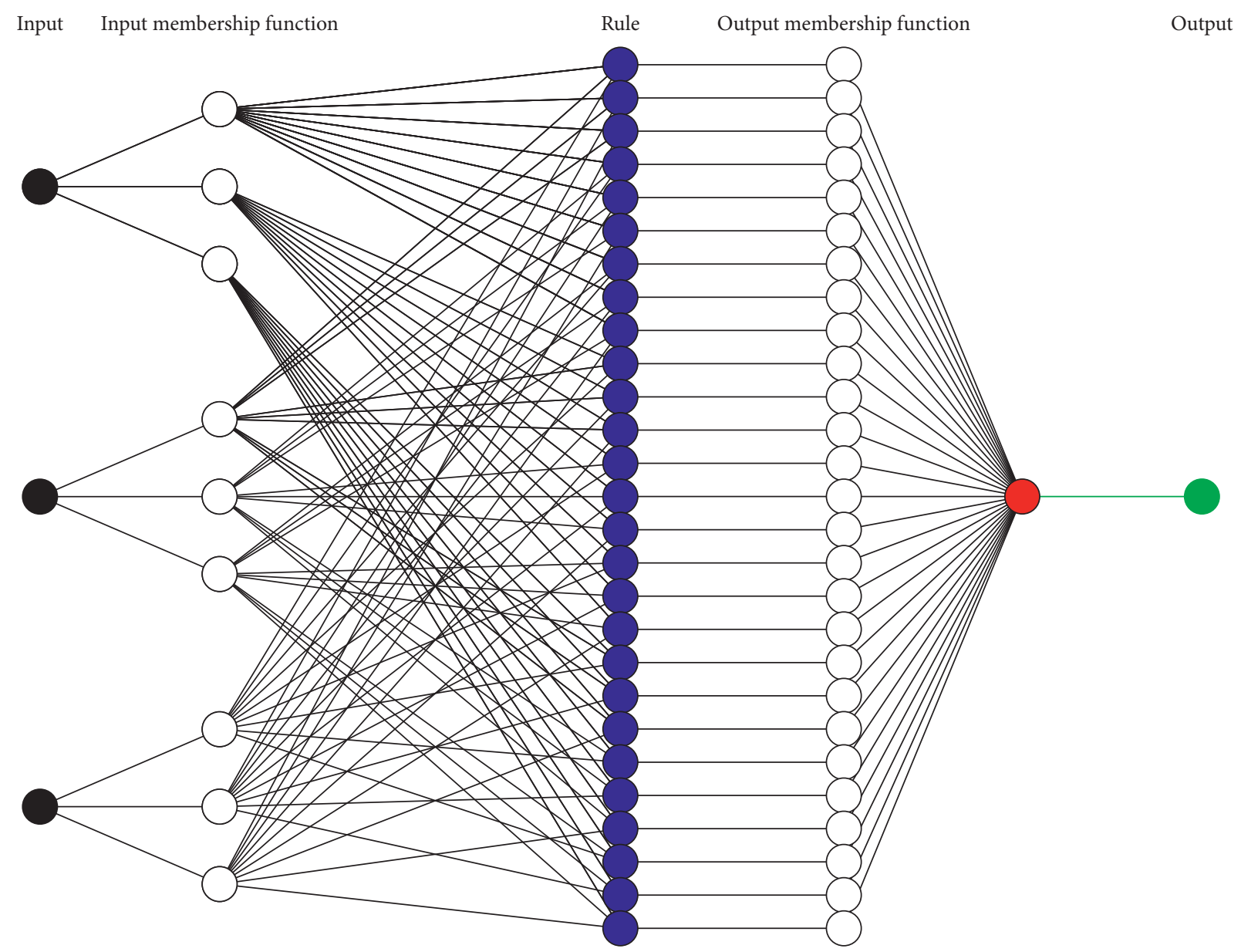

Figure 8: ANFIS architecture obtained from MATLAB Toolbox. 

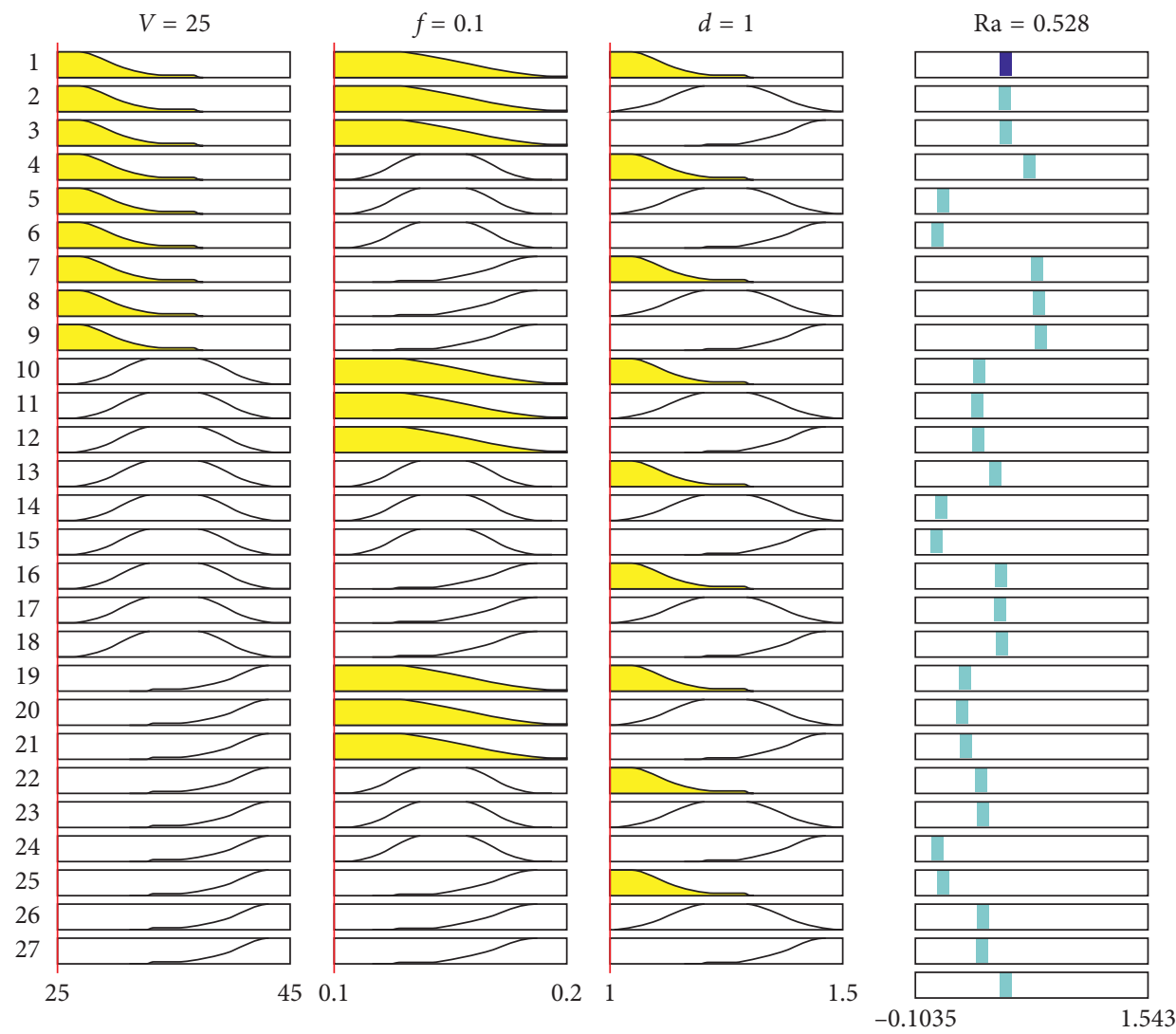

FIGURE 9: ANFIS rule viewer for Ra.

TABLE 5: Experimental data for testing and predicted response values for ANFIS model.

\begin{tabular}{|c|c|c|c|c|c|c|c|c|c|}
\hline \multirow{2}{*}{ Exp. run } & \multirow{2}{*}{$v$} & \multirow{2}{*}{$F$} & \multirow{2}{*}{$D$} & \multicolumn{2}{|c|}{$\mathrm{Ra}$} & \multicolumn{2}{|c|}{ Fc } & \multicolumn{2}{|c|}{ MRR } \\
\hline & & & & Actual & Predicted & Actual & Predicted & Actual & Predicted \\
\hline 1 & 25 & 0.1 & 1 & 0.49 & 0.528 & 676 & 682 & 2500 & 2579 \\
\hline 2 & 25 & 0.15 & 1.25 & 0.62 & 0.616 & 1085 & 1025 & 4687.5 & 4753 \\
\hline 3 & 25 & 0.15 & 1.5 & 0.62 & 0.598 & 1271 & 1286 & 5625 & 5302 \\
\hline 4 & 35 & 0.1 & 1 & 0.56 & 0.541 & 635 & 689 & 3500 & 3390 \\
\hline 5 & 35 & 0.15 & 1.5 & 0.58 & 0.562 & 1192 & 1175 & 7875 & 7427 \\
\hline 6 & 35 & 0.15 & 1.25 & 0.57 & 0.561 & 1018 & 949 & 6562.5 & 6311 \\
\hline 7 & 45 & 0.1 & 1 & 0.64 & 0.652 & 605 & 669 & 4500 & 4622 \\
\hline 8 & 45 & 0.2 & 1 & 0.63 & 0.632 & 975 & 945 & 9000 & 9234 \\
\hline 9 & 45 & 0.15 & 1.5 & 0.55 & 0.538 & 1137 & 1090 & 10125 & 10587 \\
\hline
\end{tabular}

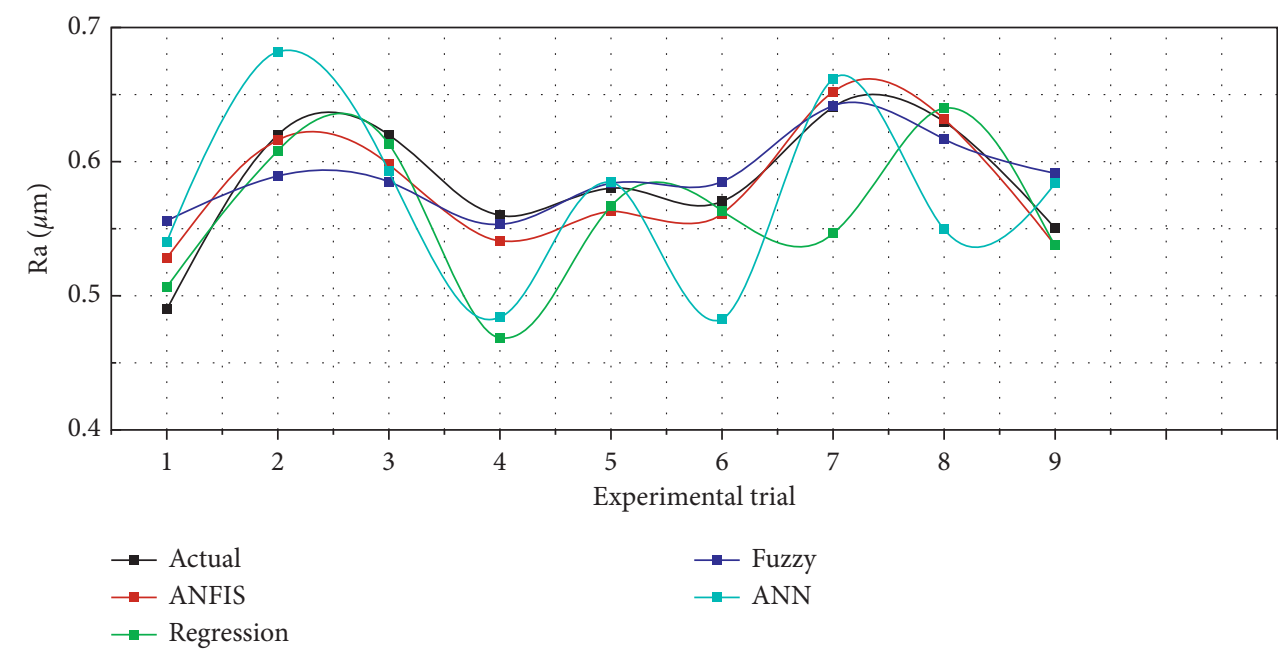

FIGURE 10: Comparison of actual and predicted response values for Ra. 


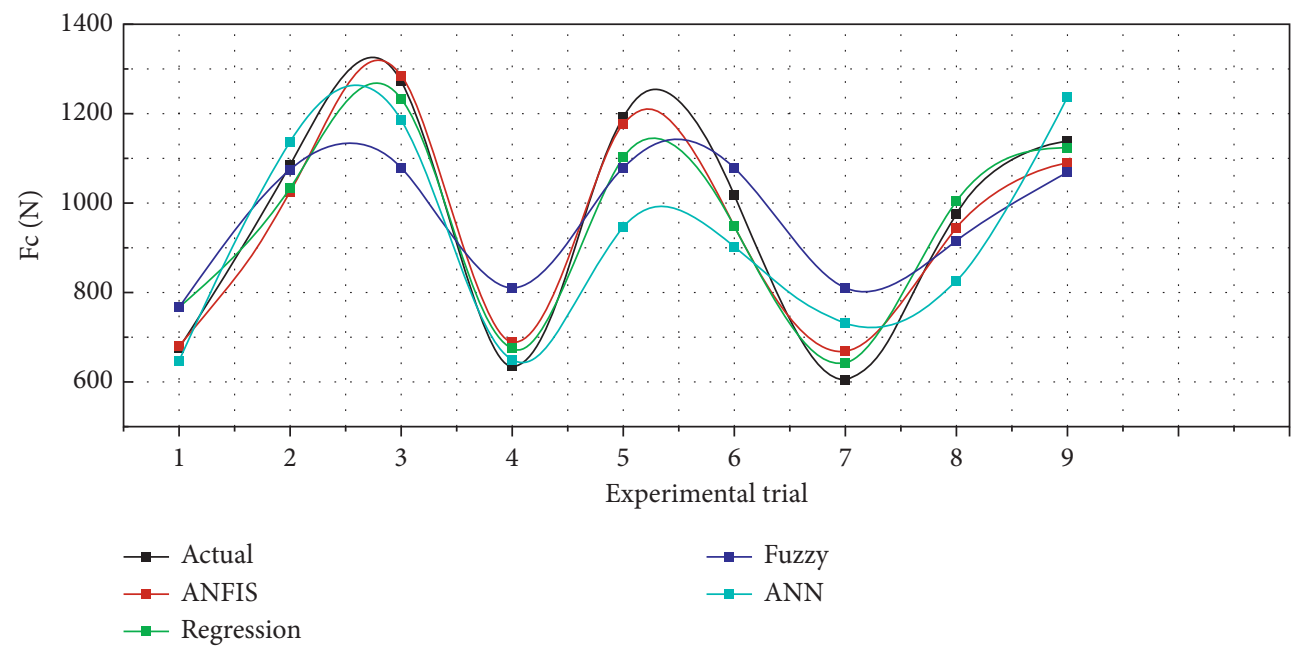

FIGURE 11: Comparison of actual and predicted response values for Fc.

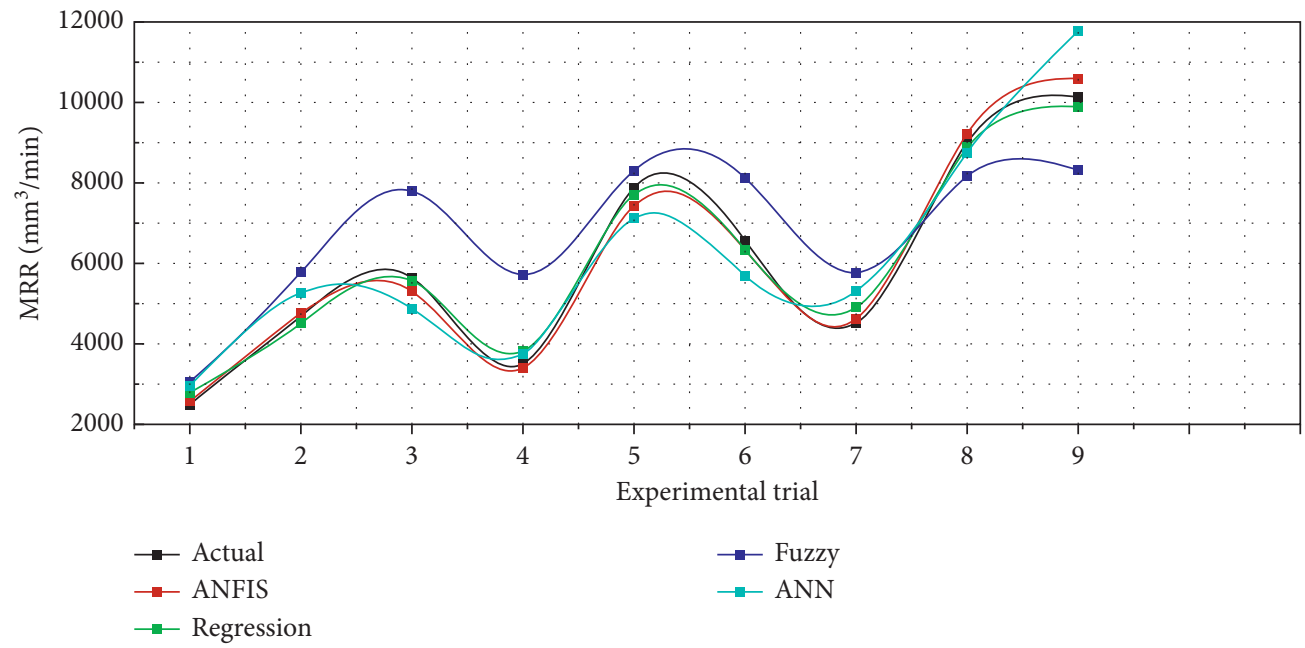

FIGURE 12: Comparison of actual and predicted response values for MRR.

TABle 6: Performance indices for different prediction tools.

\begin{tabular}{|c|c|c|c|c|c|c|c|c|c|c|c|c|}
\hline \multirow{3}{*}{ Statistical measure } & \multicolumn{12}{|c|}{ Prediction tool } \\
\hline & \multicolumn{3}{|c|}{ ANFIS } & \multicolumn{3}{|c|}{ Fuzzy logic } & \multicolumn{3}{|c|}{ ANN } & \multicolumn{3}{|c|}{ Regression } \\
\hline & $\mathrm{Ra}$ & $\mathrm{Fc}$ & MRR & $\mathrm{Ra}$ & $\mathrm{Fc}$ & MRR & $\mathrm{Ra}$ & $\mathrm{Fc}$ & MRR & $\mathrm{Ra}$ & $\mathrm{Fc}$ & MRR \\
\hline RMSPE & 3.4183 & 5.6912 & 3.8983 & 5.8422 & 16.7945 & 30.3183 & 9.7302 & 12.4016 & 13.1359 & 7.5517 & 6.8271 & 5.9817 \\
\hline MAPE & 2.7109 & 4.6772 & 3.6486 & 4.2796 & 13.2355 & 25.5936 & 8.4765 & 10.5356 & 12.2847 & 4.9769 & 5.8978 & 4.8882 \\
\hline RMSLE & 0.0716 & 0.1557 & 0.1309 & 0.0932 & 0.2573 & 0.3329 & 0.1252 & 0.2354 & 0.2353 & 0.1120 & 0.1702 & 0.1581 \\
\hline $\mathrm{R}$ & 0.8451 & 0.9736 & 0.9888 & 0.5813 & 0.8795 & 0.7491 & 0.3008 & 0.7678 & 0.9022 & 0.4776 & 0.9693 & 0.9950 \\
\hline RRSE & 0.4015 & 0.1926 & 0.1134 & 0.6830 & 0.5289 & 0.6062 & 1.2365 & 0.5067 & 0.3347 & 0.9867 & 0.2434 & 0.1015 \\
\hline
\end{tabular}




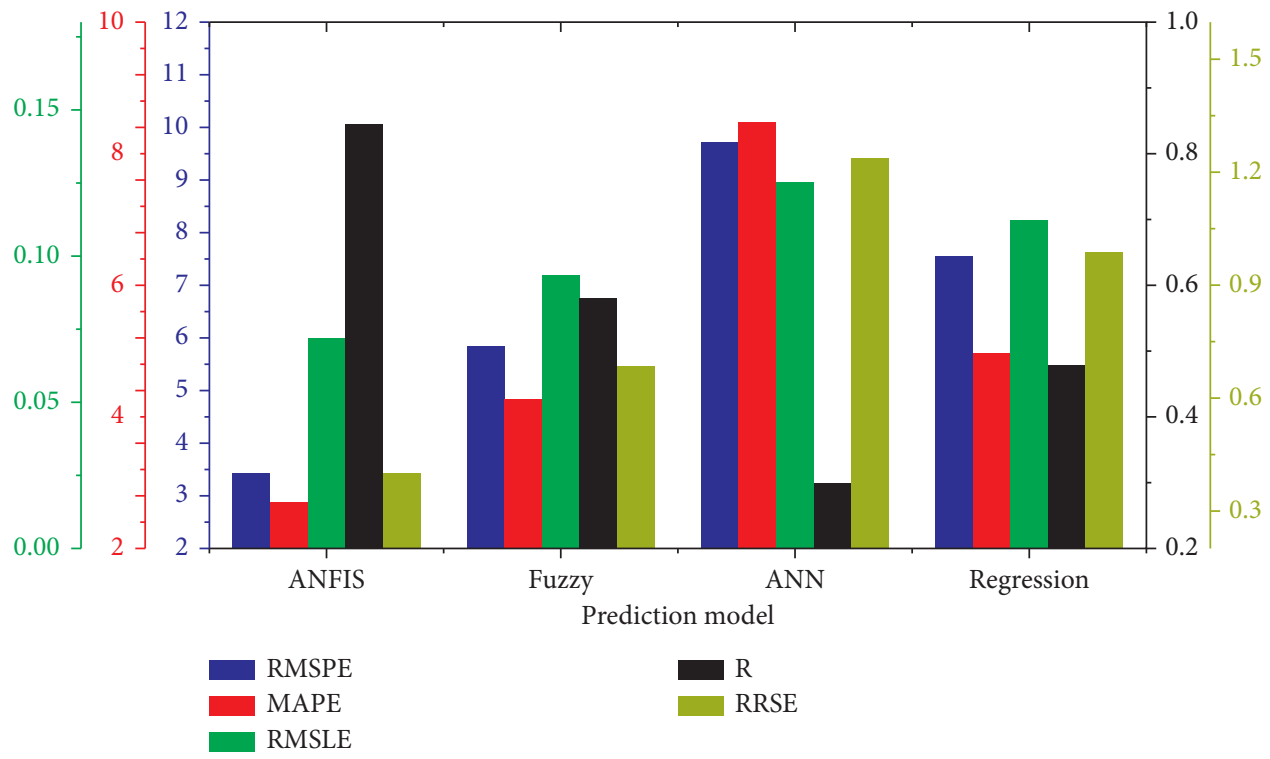

Figure 13: Performance indices of various models for Ra.

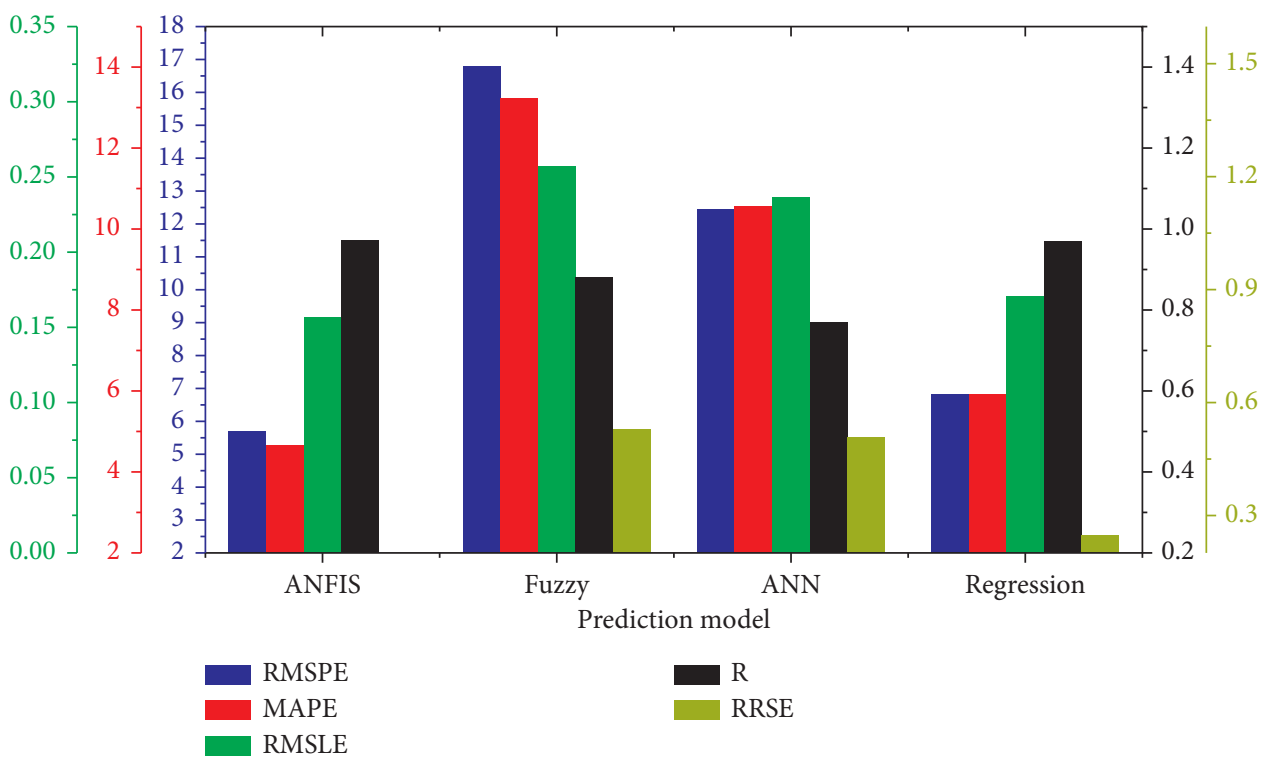

FIGURe 14: Performance indices of various models for Fc. 


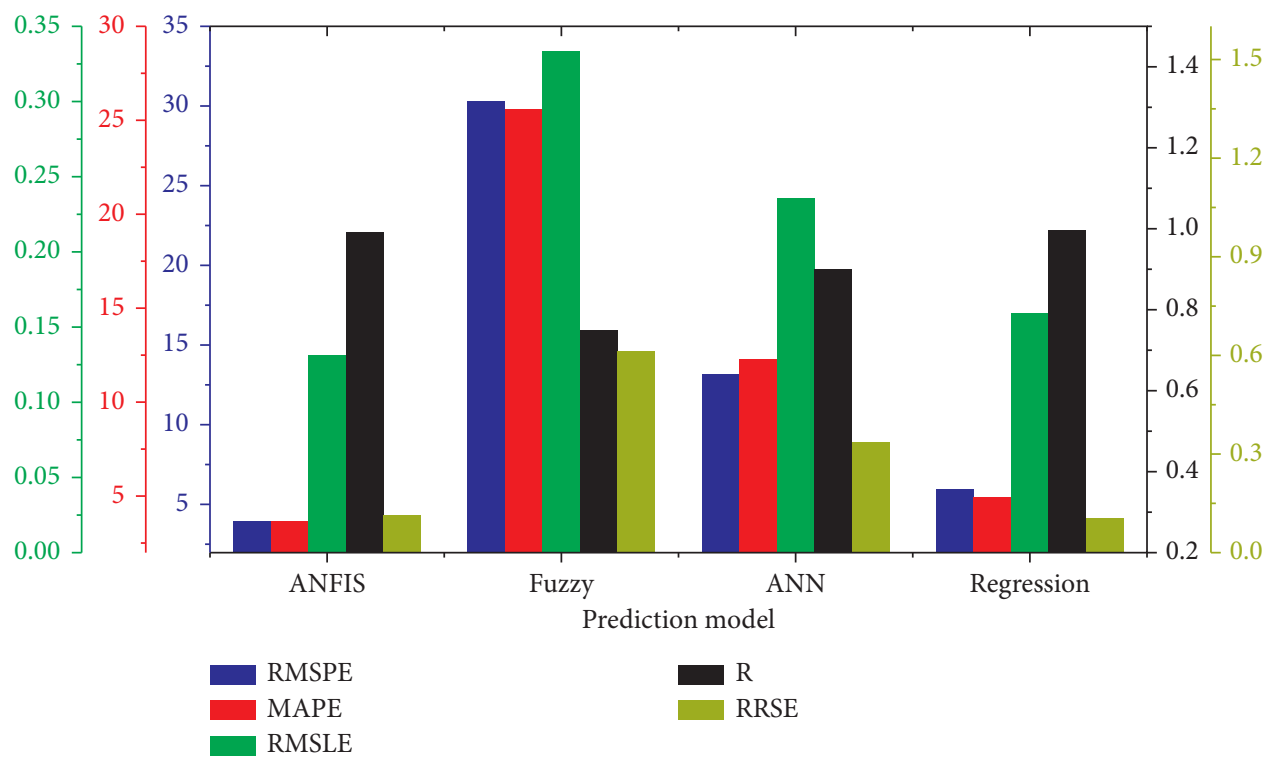

Figure 15: Performance indices of various models for MRR.

TABLE 7: Performance indices of ANFIS model for different membership functions.

\begin{tabular}{lcccccccccccc}
\hline & \multicolumn{4}{c}{ Statistical measure } & \multicolumn{3}{c}{ Generalized bell } & \multicolumn{4}{c}{ Gaussian } & \multicolumn{3}{c}{ Trapezoidal } & \multicolumn{3}{c}{ Triangular } \\
& Ra & Fc & MRR & Ra & Fc & MRR & Ra & Fc & MRR & Ra & Fc & MRR \\
\hline RMSPE & 3.4183 & 5.6912 & 3.8983 & 3.7161 & 6.3457 & 3.8466 & 3.9546 & 7.0451 & 5.4161 & 4.1897 & 9.4350 & 6.8082 \\
MAPE & 2.7109 & 4.6772 & 3.6486 & 3.3200 & 5.2817 & 3.4994 & 3.2481 & 6.6107 & 5.2262 & 3.7050 & 8.8452 & 6.6416 \\
RMSLE & 0.0716 & 0.1557 & 0.1309 & 0.0757 & 0.1628 & 0.1294 & 0.0774 & 0.1744 & 0.1531 & 0.0801 & 0.2037 & 0.1721 \\
R & 0.8451 & 0.9736 & 0.9888 & 0.8349 & 0.9670 & 0.9885 & 0.8094 & 0.9526 & 0.9776 & 0.8062 & 0.8523 & 0.9708 \\
RRSE & 0.4015 & 0.1926 & 0.1134 & 0.4547 & 0.2145 & 0.1155 & 0.4734 & 0.2685 & 0.1547 & 0.5120 & 0.3920 & 0.1861 \\
\hline
\end{tabular}

types of input membership function, that is, generalized bell, Gaussian, trapezoidal, and triangular, with respect to RMSPE, MAPE, RMSLE, $R$, and RRSE values. It can be concluded that ANFIS model with the generalized bell membership function performs best as the prediction tool for this dry turning operation of AISI 304 stainless steel material.

\section{Conclusions}

In this paper, an endeavour is put forward to compare the performances of four prediction tools, that is, regression analysis, fuzzy logic, ANN, and ANFIS models, based on a set of 27 pieces of experimental data during dry turning operation on AISI 304 stainless steel work material. Five statistical metrics, that is, RMSPE, MAPE, RMSLE, $R$, and RRSE, are deployed for this purpose. It can be noticed that the developed ANFIS model outperforms the other prediction tools with respect to all the statistical measures. Again, among different membership functions for the input variables of ANFIS model, the best prediction performance is attained while using generalized bell membership function. It is also noticed that the fuzzy logic model develops only 18 rules using the training dataset, whereas 27 rules are generated in the ANFIS model, ensuring its better prediction performance as compared to fuzzy logic model. As the ANFIS model is developed incorporating the advantageous features of both fuzzy logic and ANN, it is expected that its prediction performance would be better than its constituent elements. Although all these models are developed using only 27 experimental runs, it is quite expected that additional experimental data (generated by simulation runs) may further increase their prediction accuracy. But it has been recommended that, after a certain point, feeding more data into a predictive model dose not improve accuracy. Thus, ANFIS model can be employed as an effective tool in predicting different response values based on experimental datasets from the conventional as well as nonconventional machining processes. As a future scope, the efficacy of other variants of ANFIS model, like ANFIS grid partitioning method and ANFIS subtractive clustering method, can be verified as the prediction tools in real-time sustainable manufacturing environment.

\section{Data Availability}

No data were used to support the study.

\section{Conflicts of Interest}

The authors declare that they have no conflicts of interest. 


\section{References}

[1] U. S. Dixit, D. K. Sarma, and J. P. Davim, Environmentally Friendly Machining, Springer Science \& Business Media, Berlin, Germany, 2012.

[2] F. Schultheiss, J. Zhou, E. Gröntoft, and J.-E. Ståhl, "Sustainable machining through increasing the cutting tool utilization," Journal of Cleaner Production, vol. 59, pp. 298-307, 2013.

[3] G. Haynes, Lathe Machine Basics: Introduction to Turning Operations, Cyber Press, Santa Clara, CL, USA, 2018.

[4] H. A.-L. El-Hofy, Conventional and Nonconventional Processes, CRC Press, Boca Raton, FL, USA, 2013.

[5] P. P. Shirpurkar, S. N. Waghmare, and P. T. Date, Optimization of Turning Process, Educreation Publishing, Delhi, India, 2019.

[6] R. A. Laghari, J. Li, A. A. Laghari, and S.-Q. Wang, "A review on application of soft computing techniques in machining of particle reinforcement metal matrix composites," Archives of Computational Methods in Engineering, vol. 27, no. 5, pp. 1363-1377, 2020.

[7] M. M. Koura, T. H. Sayed, and A. S. El-Akkad, "Modeling and prediction of surface roughness during dry turning process," International Journal of Engineering Research \& Technology, vol. 3, no. 7, pp. 694-699, 2014.

[8] M. Hanief and M. F. Wani, "Influence of cutting parameters on surface roughness of red brass (C23000) in turning using exponential model," Hidraulica, vol. 3, pp. 55-58, 2015.

[9] M. Mia, M. Al Bashir, and N. R. Dhar, "Effects of cutting parameters and machining environments on surface roughness in hard turning using design of experiment," AIP Conference Proceedings, vol. 175, Article ID 060012, 2016.

[10] S. Benlahmidi, H. Aouici, F. Boutaghane, A. Khellaf, B. Fnides, and M. Yallese, "Design optimization of cutting parameters when turning hardened AISI H11 steel (50 HRC) with CBN7020 tools," The International Journal of Advanced Manufacturing Technology, vol. 89, no. 1-4, pp. 803-820, 2017.

[11] A. V. N. L. Sharma and G. Krishnaiah, "Analysis and evaluation of machining responses during hard turning of EN353 steel," International Journal of Mechanical and Production Engineering Research and Development, vol. 7, no. 2, pp. 167-176, 2017.

[12] A. Panda, A. K. Sahoo, I. Panigrahi, and R. Kumar, "Tool condition monitoring during hard turning of AISI 52100 steel: a case study," Materials Today: Proceedings, vol. 5, no. 9, pp. 18585-18592, 2018.

[13] K. Pawan and J. P. Misra, "A surface roughness predictive model for DSS longitudinal turning operation," DAAAM International Scientific Book, vol. 25, pp. 285-296, 2018.

[14] H. Aouici, M. Elbah, A. Benkhelladi, B. Fnides, L. Boulanouar, and M. A. Yallese, "Comparison on various machinability aspects between mixed and reinforced ceramics when machining hardened steels," Mechanics \& Industry, vol. 20, no. 1, p. 109, 2019.

[15] M. Elbah, H. Laouici, S. Benlahmidi, M. Nouioua, and M. Yallese, "Comparative assessment of machining environments (dry, wet and MQL) in hard turning of AISI 4140 steel with CC6050 tools," The International Journal of Advanced Manufacturing Technology, vol. 105, no. 5-6, pp. 2581-2597, 2019.

[16] S. K. Rajbongshi and D. K. Sarma, "A comparative study in prediction of surface roughness and flank wear using artificial neural network and response surface methodology method during hard turning in dry and forced air-cooling condition,"
International Journal of Machining and Machinability of Materials, vol. 21, no. 6, pp. 390-436, 2019.

[17] M. S. Alajmi and A. M. Almeshal, "Prediction and optimization of surface roughness in a turning process using the ANFIS-QPSO method," Materials, vol. 13, pp. 13-21, 2020.

[18] D. Cica, B. Sredanovic, S. Tesic, and D. Kramar, "Predictive modeling of turning operations under different cooling/lubricating conditions for sustainable manufacturing with machine learning techniques," Applied Computing and Informatics, vol. 145, no. 6, 2020.

[19] A. Panda, A. K. Sahoo, I. Panigrahi, and A. K. Rout, "Prediction models for on-line cutting tool and machined surface condition monitoring during hard turning considering vibration signal," Mechanics \& Industry, vol. 21, no. 5, p. 520, 2020.

[20] S. Setia and S. R. Chauhan, Comparative Analysis and Optimization of Fem and Rsm Based Regression Model with Experimental Results for the Dry Turning of Sicp-Al7075 Composite, Springer, Berlin, Germany, 2020.

[21] L. A. Zadeh, "Fuzzy sets," Information and Control, vol. 8, no. 3, pp. 338-353, 1965.

[22] S. Chakraborty, P. P. Das, and V. Kumar, "Application of grey-fuzzy logic technique for parametric optimization of non-traditional machining processes," Grey Systems: Theory and Application, vol. 8, no. 1, pp. 46-68, 2018.

[23] S. Chakraborty and P. P. Das, "Fuzzy modeling and parametric analysis of non-traditional machining processes," Management and Production Engineering Review, vol. 10, no. 3, pp. 111-123, 2019.

[24] V. Kumar, P. P. Das, and S. Chakraborty, "Grey-fuzzy method-based parametric analysis of abrasive water jet machining on GFRP composites," Sadhana, vol. 45, p. 106, 2020.

[25] K. Gurney, An Introduction to Neural Networks, Taylor \& Francis, London, UK, 2005.

[26] J.-S. R. Jang, "ANFIS: adaptive-network-based fuzzy inference system," IEEE Transactions on Systems, Man, and Cybernetics, vol. 23, no. 3, pp. 665-685, 1993.

[27] S. R. Jang, C. T. Sun, and E. Mizutani, Neuro Fuzzy and Soft Computing, Prentice Hall International, Hoboken, NJ. USA, 1997.

[28] U. Çaydaş, A. Hasçalık, and S. Ekici, "An adaptive neurofuzzy inference system (ANFIS) model for wire-EDM," Expert Systems with Applications, vol. 36, pp. 6135-6139, 2009.

[29] R. B. Azhiri, R. Teimouri, M. G. Baboly, and Z. Leseman, "Application of Taguchi, ANFIS and grey relational analysis for studying, modeling and optimization of wire EDM process while using gaseous media," International Journal of Advanced Manufacturing Technology, vol. 71, pp. 279-295, 2014.

[30] A. Abdulshahed and I. Badi, "Prediction and control of the surface roughness for the end milling process using ANFIS," Operational Research in Engineering Sciences: Theory and Applications, vol. 1, no. 1, pp. 1-12, 2018.

[31] S. K. Nayak, S. Dewangan, S. Gangopadhyay, and S. Gangopadhyay, "Multi-objective optimization of machining parameters during dry turning of AISI 304 austenitic stainless steel using grey relational analysis," Procedia Materials Science, vol. 6, pp. 701-708, 2014. 